\title{
Comment
}

\section{Listening and empowering: children and science communication}

\section{Matteo Merzagora and Tricia Jenkins}

\begin{abstract}
In the editorial of this issue of JCOM, we underline how children are on one hand one of the main target group for science communication, and on the other hand a largely excluded group in the shift from a linear diffusion model to a dialogic model of science communication.

In this series of comments, stimulated by the EU - FP7-Science in society project "SiS-Catalyst - children as change agents for science in society" (a four year programme aimed at crossing the science in society and the social inclusion agendas), we would like to explore methods and approaches that can ensure that, in science communication contexts, children can be listened to, that they are given the chance to express their view, and that they can be empowered in building their own relationship with science, and thus a sense of ownership for scientific knowledge.
\end{abstract}

In the editorial of this issue of JCOM, ${ }^{1}$ we underline how children are on one hand one of the main target groups for science communication (for a number of different and often contradictory reasons) and, on the other hand, a largely excluded group in the shift from a linear diffusion model to a dialogic model of science communication.

In this series of comments (stimulated by the EU - FP7-Science in society project "SiS-Catalyst - children as change agents for science in society", a four-year project aimed at crossing the science in society and the social inclusion agendas) we would like to explore methods and approaches that can ensure that, in science communication contexts, children can be listened to, that they are given the chance to express their view, and that they can be empowered in building their own relationship with science, and thus a sense of ownership for scientific knowledge.

The question is not purely abstract. When we talk about science we are talking about the future, thus about something that affects the child. In this context, listening to children and empowering them is not just a choice, but an obligation for all states who signed the UN convention on the rights of the child. Indeed, article 12 states that we "shall assure to the child who is capable of forming his or her own views the right to express those views freely in all matters affecting the child, the views of the child being given due weight in accordance with the age and maturity of the child". Which links do or shall exist between these fundamental principles endorsed by our governments and science communication activities addressing children? 
In their text, Laura Lundy and Elizabeth Welty help us understand what article 12 really means, and more specifically what it means to implement it in practical terms. But listening to children is also a great opportunity to improve science communication practices. Christian Gary and Karoline Iber analyse this aspect from the perspective of the Children's University Network (Eucu.net), a fast growing network for which the inclusion of children's voices is increasingly a key preoccupation. In this perspective, a crucial element is the organisation of spaces where a dialogue with children can take place, and where they can eventually contribute to the governance of the science communication activities. In their paper, Andrea Bou-Vinals and Silvia Prock analyse the approach of Innsbruck's children's university in setting up a children advisory board for their activities, and points to another important issue: the training of scientists to interact with young audiences, and in particular the perspective of involving children in training scientists to talk to them.

Finally, there are many examples in which children are empowered in practice to develop a true ownership for scientific knowledge. These include a great variety of approaches, such as:

- the growing relevance of "citizen science" activities (from the seminal experiences on ornithology of Cornell University, to the activities on biodiversity of Museum National d'Histoire Naturel de Paris, to particularly innovative approaches such as the Tierra de Niños activity of Mundo de Ania in Lima, Peru);

- the implication of children in the co-design of spaces devoted to them (from the design of the children's space at the Città della Scienza in Naples, to the contribution of children to the design of ZOOM kindermuseum in Vienna);

- the creation of personal, creative productions - an art-piece, a story, a film - as a driver for the appropriation of scientific knowledge (such as the Tinkering

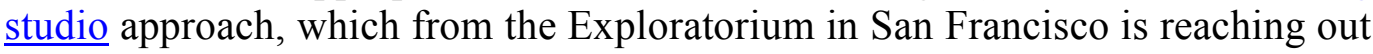
globally, to the "Tell your science"/KiiCS program that has teenagers shoot fiction films on science topics, organized by Traces/Espace de sciences PierreGilles de Gennes, Paris);

- the use of a journalistic approach in which children are not only executors, but the true decision-makers in organising and defining the relevance of the scientific content. On this latter aspect, Paola Rodari and Simona Cerrato propose two innovative case studies involving children and teenagers in Trieste and in Sardinia, respectively.

Overall, this limited set of comments clearly indicates the multiple, wonderful opportunities offered by the capacity to release control on children's learning and provide spaces for empowerment: opportunities both in terms of the resulting quality of science communication, and on the potential institutional impact. Through such an approach, science in the perception of young people can indeed become a tool to design a world as close as possible to the world in which they would like to live, rather than external knowledge that a child just needs to learn in order to live in whatever world is proposed to him or her. As stated by the founder of San 
Francisco's Exploratorium Frank Oppenheimer in 1969, "If people feel they understand the world around them or, probably, even if they have the conviction that they could understand it if they wanted to, then and only then are they also able to feel that they can make a difference through their decisions and activities."

One essential element remains in the background of these considerations: is the way science is presented to the young public socially inclusive? If on one hand science is undeniably offering opportunities to overcome forms of oppression and exclusion, on the other hand the science education pathways can be implicitly at the origin of discriminatory process. In fact, a solid structured form of knowledge such as science can be perceived very differently by children with a higher socio-economic background (for whom science can be an opportunity of success) and those coming from disadvantaged areas or local minorities (for whom science can be mainly an instrument of selection for progression into higher education, and something that strengthens the separation between a future "for them" and a future "for me").

\title{
Notes and references
}

${ }^{1}$ M. Merzagora and P. Rodari (2013), "The challenges and the opportunities of letting children have their say", JCOM 12(03): E

\begin{abstract}
Authors
Matteo Merzagora is scientific director of the TRACES science communication think-and-do tank in Paris, and director of programs of the science culture centre Espace de sciences Pierre-Gilles de Gennes - ESPCI ParisTech. He is currently involved in several programs linking the science in society and the social inclusion agendas, and using arts and culture as a way to empower citizens with respect to scientific knowledge. Among his latest exhibitions: La science, une histoire d'humour (a 100\% crowd-sourced exhibition on science and humor) and Les invisibles (an art-science exhibition on the fascinations and the worries that science generates when it unveils new invisibles). E-mail: merzagora@gmail.com.
\end{abstract}

Tricia Alegra Jenkins MBE is an innovative educator with a growing international profile. She is the Director of the International Centre for Excellence in Educational Opportunities at the University of Liverpool, where she has worked for over 25 years. As President of the European Children's Universities Network and Principal Investigator of the Mobilising Mutual Learning Action Plan - SiS Catalyst: Children as Change Agents for Science and Society, she travels extensively promoting the concept of social inclusion and institutional change through the active learning, from and with children.

E-mail: P.M.Jenkins@liverpool.ac.uk.

How TO CITE: M. Merzagora and T. Jenkins (2013), "Listening and empowering: children and science communication", JCOM 12(03): C01. 